\title{
EVALUACIÓN MICROBIOLÓGICA DE CARCASAS DE POLLO Y AMBIENTES DE CENTROS DE FAENAMIENTO, EN UNA PROVINCIA DE LA AMAZONÍA PERUANA
}

\author{
Microbiological evaluation of chicken carcasses and environments \\ of slaughtering centers in a province of the Peruvian Amazon
}

D Cyndi Tatiana Cabrera Marino ${ }^{1}$

E-mail:cabrera_marino@hotmail.com

Nidia Llapapasca García ${ }^{3}$

E-mail:nllapapascag@unmsm.edu.pe
Juan Alexander Rondón Espinoza ${ }^{2^{*}}$

E-mail: jrondone@unmsm.edu.pe

Lluvis Lucero Germany Grandez ${ }^{4}$ E-mail: lucerogermany@gmail.com

Manuel de la Torre Villanueva ${ }^{5}$ E-mail: mdelatorre v@hotmail.com

'Médico Veterinario, Facultad de Medicina Veterinaria, Universidad Alas Peruanas, filial Pucallpa, Perú. ${ }^{2}$ Docente, Estación del Centro de Investigación IVITA Pucallpa, Facultad de Medicina Veterinaria, Universidad Nacional Mayor de San Marcos, Ucayali, Perú. Grupo de investigación Salud pública y salud ambiental ${ }^{3}$ Docente, Estación del Centro de Investigación IVITA Pucallpa, Facultad de Medicina Veterinaria, Universidad Nacional Mayor de San Marcos, Ucayali, Perú. Grupo de investigación Biodiversidad, conservación y producción sostenible ${ }^{4}$ Médico Veterinario, asistente técnico, Estación del Centro de Investigación IVITA Pucallpa, Facultad de Medicina Veterinaria, Universidad Nacional Mayor de San Marcos, Ucayali, Perú.

${ }^{5}$ Profesor cesante, Facultad de Medicina Veterinaria, Universidad Alas Peruanas, filial Pucallpa, Perú.

Fecha recepción: 16 de junio de 2021 / Fecha Aprobación: 28 de junio 2021 / Fecha Publicación: 30 de julio 2021

\section{RESUMEN}

El objetivo del presente estudio fue llevar a cabo una evaluación microbiológica de carcasas de pollo y de los ambientes de los centros de faenamiento avícola, en la provincia de Coronel Portillo, Ucayali, en Perú. Para ello, se recolectaron muestras de 30 carcasas de pollo y de seis ambientes, provenientes de seis centros de faenamiento (CF), dos centros formales y cuatro centros informales; lo anterior, mediante un muestreo no probabilístico por conveniencia. Las muestras de las carcasas se tomaron mediante el método de hisopado de superficie; las muestras de los ambientes se obtuvieron mediante el plaqueo ambiental. En las carcasas se encontró Escherichia coli, Enterobacter cloacae, Proteus spp, Salmonella spp. y Bacillus spp, con recuentos de bacterias mesófilas aerobias, superiores a los límites máximos permisibles (LMP), de $5 \mathrm{Log} \mathrm{UFC} / \mathrm{cm}^{2}$ en 2 CFI. También se encontraron recuentos de enterobacterias por encima a $2 \mathrm{Log} \mathrm{UFC} / \mathrm{cm}^{2}$, en todas las muestras. Los ambientes tuvieron promedios de recuentos de 3,11 \pm 1,28 Log UFC/placa de mesófilos aerobios; de 1,34 \pm 0,49 Log UFC/placa de enterobacterias, y de 39,17 $\pm 50,06 \mathrm{UFC} /$ placa de hongos. La evaluación permitió observar la presencia de varios géneros bacterianos en las carcasas de pollo, en los seis centros de faenamiento, especialmente en los centros informales, con valores en los recuentos de aerobios mesófilos, que

\section{Cómo citar:}

Cabrera Marino, C.T., Rondón Espinoza, J.A., Llapapasca García, N., Germany Grandez, Ll.L., Torre Villanueva, M. (2021). Evaluación microbiológica de carcasas de pollo y ambientes de centros de faenamiento, en una provincia de la Amazonía Peruana. Revista Facultad de Ciencias Agropecuarias -FAGROPEC. Universidad de la Amazonia. Vol. 13 (2), 100-113. https://doi.org/10.47847/fagropec.v13n2a2 
Evaluación microbiológica de carcasas de pollo y ambientes de centros de faenamiento...

sobrepasan los límites máximos permisibles (LMP). Además, se encontraron cargas muy elevadas de bacterias y de hongos en sus ambientes.

\section{Palabras claves.}

hisopados, plaqueo ambiental, probabilístico, bacterias mesófilas aerobias, enterobacterias.

\section{ABSTRACT}

The objective of the study was to carry out a microbiological evaluation of chicken carcasses and the environments of the poultry slaughter centers in the province of Coronel Portillo, Ucayali - Perú. Samples of 30 chicken carcasses and six environments were collected from six slaughter centers (CF) (two formal centers and four informal centers), through non-probability sampling for convenience. Carcass samples were taken using the surface swab method and environmental samples by environmental plating. Escherichia coli, Enterobacter cloacae, Proteus spp, Salmonella spp and Bacillus spp were found in the carcasses, with counts of aerobic mesophilic bacteria above the maximum permissible limits (MPL) of $5 \mathrm{Log}$ CFU / $\mathrm{cm} 2$ in $2 \mathrm{CFI}$, as well as counts of Enterobacteriaceae. above $2 \log \mathrm{CFU} / \mathrm{cm} 2$ in all samples. The environments had mean counts of 3.11 $\pm 1.28 \mathrm{Log}$ CFU / plate of aerobic mesophiles, $1.34 \pm 0.49 \mathrm{Log}$ CFU / plate of Enterobacteriaceae and $39.17 \pm 50.06 \mathrm{CFU} /$ plate of fungi. The evaluation demonstrated the presence of several bacterial genera in the chicken carcasses in the six slaughter centers, especially in the informal centers, with values in the mesophilic aerobic counts that exceed the maximum permissible limits (MPL), in addition to very high loads. of bacteria and fungi in their environments.

Key words: swabs, environmental plating, probabilistic, aerobic mesophilic bacteria, enterobacteria.

\section{INTRODUCCIÓN}

La producción avícola representa el 28\% del total de la producción agropecuaria del Perú, por lo que se promedia que, en el país, el consumo de pollo puede llegar a los $50 \mathrm{~kg} / \mathrm{hab} / \mathrm{año}$ (Avinews, 2019; Instituto Nacional de Estadística e Informática [INEI]). Adicionalmente, en la Amazonía Peruana la producción avícola es una de las actividades que ha crecido en la última década, lo que ha generado que el consumo per cápita, de carne de aves de engorde, se incremente y supere a la de las otras especies, incluso a la del pescado (Vera, 2016).

Una de las regiones de la Amazonía que muestra más crecimiento en la crianza avícola es la de Ucayali. En ella, gracias a la importante demanda, desde el año 2016 se han producido 336596 aves por mes, superando el déficit de los años anteriores (Linares, 2017). Este incremento ha conllevado al aumento en la cantidad de aves beneficiadas, para el consumo de la población. No obstante, uno de los mayores riesgos asociados con este crecimiento acelerado, está relacionado con la ausencia de centros de beneficio que sean apropiados, y que, a su vez, permitan la implementación de las Buenas Prácticas de Faenamiento, para que, con estas, se logre garantizar la inocuidad del producto final.

Por su parte, en la provincia de Coronel Portillo, Ucayali, existen 18 centros de faenamiento, varios de ellos informales, los cuales además no cumplen con los requisitos sanitarios que han 
sido establecidos por la autoridad reguladora. En estos centros se realizan actividades de faenado con escasa bioseguridad, por lo que, en la mayoría de los casos, el proceso de faenamiento de aves llega solo hasta el desplumado, dejando el pollo entero sin eviscerar, y, en esas condiciones, suele ser distribuido a los comercializadores minoristas (Zegarra et al., 2004).

Así las cosas, se entiende que al finalizar el proceso de faenamiento se puede encontrar una baja carga microbiana en las carcasas de las aves, pero la contaminación microbiana puede incrementarse en un ambiente contaminado, cuando existen procedimientos deficientes del faenamiento (Servicio Nacional de Sanidad y Calidad Agroalimentaria. Ministerio de Agroindustria de Argentina [SENASA], 2016). Consecuente con esto, se puede encontrar gran diversidad de microorganismos en las carcasas, algunos de los cuales pueden ser patógenos, capaces de producir enfermedades en el humano (Chen, Fegan, Kocharunchitt, Bowman y Duffy, 2020; Pérez, 2015).

Así bien, el aumento en la incidencia de enfermedades transmitidas por alimentos, durante las últimas décadas, parece guardar relación con un aumento de las enfermedades provocadas por microorganismos y por toxinas presentes (Organización de las Naciones Unidas para la Agricultura y la Alimentación / Organización Mundial de la Salud [FAO /OMS], 2015); ello, sugiere una ausencia de control de calidad de los productos avícolas, en los centros de faenamiento y en los mercados del país. Así entonces, el presente trabajo tuvo como objetivo realizar una evaluación microbiológica en carcasas de aves y en los ambientes de los centros de faenamiento, en una provincia ubicada en la Amazonía Peruana.

\section{MATERIALES Y MÉTODOS}

\section{Lugar y periodo de tiempo del estudio}

El presente estudio se realizó en la provincia de Coronel Portillo, en la región de Ucayali, la cual se encuentra ubicada en la zona centro oriental del Perú. El lugar mencionado tiene un clima tropical húmedo, con temperaturas que oscilan entre los 18,7 y los $33,1^{\circ} \mathrm{C}$; además, muestra una precipitación promedio anual de $1563 \mathrm{~mm}$ (Servicio Nacional de Meteorología e Hidrología del Perú [SENHAMI], 2017). El procesamiento de muestras se realizó en la Unidad de Diagnóstico en Laboratorio, de la Sección de Sanidad Animal, del Instituto Veterinario de Investigaciones Tropicales y de Altura (IVITA), sede Pucallpa, perteneciente a la Facultad de Medicina Veterinaria de la Universidad Nacional Mayor de San Marcos. El estudio se desarrolló entre el mes de diciembre de 2016 y el mes de abril de 2017.

\section{Selección y caracterización de los centros de faenamiento}

Para el presente estudio fueron seleccionados seis centros de faenamiento avícola (CFA) en actividad, de la provincia de Coronel Portillo, los cuales se encontraban distribuidos en los 
distritos de Callería (4), Yarinacocha (1) y Manantay (1): De entre estos, dos fueron centros formales (CFF) y cuatro fueron informales (CFI). En cuanto a su infraestructura, dos de los CFI tenían instalaciones de madera y los demás CF contaban con instalaciones de concreto. Además, en los CFI, los procesos se realizaban en un solo ambiente, mientras que en los CFF se realizaban en dos a cuatro ambientes, separando los procesos. Los CFI contaban con un personal de hasta cinco operarios y los CFF contaban con un personal de seis o más operarios.

El proceso de faenamiento iniciaba con la recepción de los pollos, los cuales permanecían, durante un promedio de tiempo de entre dos a seis horas, en un área contigua externa al CF, para los centros informales, y en un área de espera para los centros formales. El sacrificio era manual en casi todos los centros, a excepción de un centro formal, en el cual dicho proceso era de tipo mecánico. Posterior a los procesos de desangrado y de escaldado, el eviscerado solo se realizaba en un centro formal. Tres centros informales trabajaban con agua almacenada en tanque; el resto de los centros contaban con agua potable permanente. Los centros formales contaban con un sistema de drenaje de aguas residuales y de disposición de residuos sólidos. Los pollos faenados permanecían en el área de despacho, entre una hasta tres horas para su salida; solo un centro formal manejaba cadena de frío después del faenado. El mobiliario y los utensilios utilizados en los centros informales eran básicos, mientras que en los centros formales eran sofisticados e higiénicos. Para encontrar más detalles al respecto tabla 1.

Tabla 1.

Parámetros de infraestructura y equipamiento para los procesos de faenamiento de centros formales e informales.

\begin{tabular}{lccc}
\hline Centros de Faenamiento & & Informal & Formal \\
\hline Infraestructura & Madera & 2 & - \\
& Concreto & - & 4 \\
$\mathrm{~N}^{\circ}$ de Instalaciones & - & 4 & 2 \\
Recepción & & $\mathrm{Si}$ & $\mathrm{Si}$ \\
Aturdimiento & & $\mathrm{No}$ & $\mathrm{Si}$ \\
Sacrificio y Desangrado & & 4 & 2 \\
Escaldado y Desplume & & 4 & 2 \\
Lavado 1 & & 4 & 2 \\
Evisceración & & $\mathrm{No}$ & $\mathrm{Si}$ \\
Lavado 2 & & $\mathrm{No}$ & $\mathrm{Si}$ \\
Oreo & & $\mathrm{No}$ & $\mathrm{Si}$ \\
Expendio & & $\mathrm{No}$ & $\mathrm{Si}$ \\
Indumentaria & Adecuada & - & 2 \\
& Inadecuada & 4 & - \\
Mobiliario y Utensilios & Higiénicos & $\mathrm{No}$ & $\mathrm{Si}$ \\
\hline
\end{tabular}




\section{Diseño del estudio}

La presente investigación no experimental es un estudio de tipo observacional. Para este se realiza un muestreo no probabilístico por conveniencia, de seis centros de faenamiento, de tres distritos, en la provincia de Coronel Portillo (haciéndolo de manera proporcional respecto de la cantidad de centros por distrito). Igualmente, para el mismo tipo de muestreo de las carcasas, en cada centro (considerando una muestra representativa de cinco carcasas de pollo como un lote de producción), este último criterio es considerado con base en la Norma Técnica de Salud N 071-2008 (Ministerio de Salud del Perú / Dirección General de Salud Ambiental [MINSA / DIGESA], 2008). Adicionalmente, se toma una muestra del ambiente principal de cada centro de faenamiento, mediante plaqueo ambiental.

\section{Recolección y procesamiento de las muestras}

\section{Recolección}

La recolección de la muestra se realizó entre las 3:00 y las 4:00 a.m., a la mitad del tiempo del proceso de faenamiento, el cual se iniciaba a las 00:00 y finalizaba a las 06:00. Se aplicó la técnica de hisopado de superficies inertes, de acuerdo con la American Public Health Association (APHA) y con la Guía Técnica para el Análisis Microbiológico y de Superficies en Contacto con Alimentos y Bebidas, descrito por MINSA/ DIGESA, (2008).

Para el método de hisopado se frotó un hisopo estéril previamente humedecido, en una solución de $5 \mathrm{ml}$ de agua peptonada estéril, contenida en un tubo, sobre el área determinada de muestreo de las regiones dorsolumbar y del muslo, usando una plantilla estéril de $25 \mathrm{~cm}^{2}$ (5x 5 $\mathrm{cm})$. El hisopo humedecido se presionó ligeramente en la pared del tubo, con un movimiento de rotación, con el fin de quitar el exceso de solución; luego fue inclinado en un ángulo de $30^{\circ}$ y se frotó cuatro veces la superficie delimitada por la plantilla, cada una en dirección opuesta a la anterior, para asegurar el hisopado en toda la superficie. Además, se colocaron los dos hisopos (de la zona dorsolumbar y del muslo) del lado izquierdo y derecho de la carcasa en el tubo, quebrando y eliminando la parte del hisopo que estuvo en contacto con los dedos.

Para el plaqueo ambiental se utilizaron tres placas de Petri, con medios de cultivo [Agar Tripticasa Soya (TSA), Agar MacConkey (MC) y Agar Sabouraud Dextrosa (AS)], en el ambiente principal del centro de faenamiento. Se consideró el área final del proceso de faenamiento para los centros formales. Las placas se dejaron abiertas durante 15 minutos, en forma de triángulo equilátero. Todas las muestras se llevaron al laboratorio en un cooler con geles refrigerantes, conservando las muestras entre 2 a $8^{\circ} \mathrm{C}$, hasta su procesamiento.

\section{Procesamiento}

De los tubos con las muestras del hisopado, el tubo 1 se procesó en forma directa para el aislamiento de mesófilos aerobios y el tubo 2 fue incubado para el descarte de Salmonella spp. 
Del contenido del tubo 1 se realizaron diluciones $10^{-2}, 10^{-3}$ y $10^{-4}$ en otros tubos, conteniendo 5 $\mathrm{ml}$ de una solución buffer fosfato (PBS); luego, $1 \mathrm{ml}$ de esta segunda dilución fue inoculado en placas conteniendo TSA y Agar MC, con movimientos manuales en forma de cruz, durante sesenta segundos, hasta la dispersión completa de la muestra en el medio de cultivo. Posterior a ello, las placas fueron incubadas a $36,5^{\circ} \mathrm{C}$ por $24 \mathrm{~h}$. El contenido del tubo 2 fue incubado a $36,5^{\circ} \mathrm{C}$ por $24 \mathrm{~h}$, para posteriormente homogenizar e inocular $1 \mathrm{ml}$ de este contenido en Agar $\mathrm{MC}$ (por el mismo método).

De las muestras obtenidas en el plaqueo ambiental, las placas con TSA y Agar MC se incubaron a $36,5^{\circ} \mathrm{C}$ por $24 \mathrm{~h}$, mientras que las placas con Agar Sabouraud fueron incubadas a $30^{\circ} \mathrm{C}$ por cinco días.

\section{Identificación y recuento microbiano}

Se realizó el recuento bacterial y la identificación de los géneros bacterianos más comunes en los cultivos de TSA y Agar MC. El recuento se realizó con un contador de colonias y la identificación se realizó mediante fenotipificación de las colonias, tinción Gram y pruebas bioquímicas. Para la identificación de Escherichia coli y de otras enterobacterias se utilizaron los medios Citrato, Agar hierro-triple azúcar (TSI) e Indol. Para la identificación de Salmonella spp. se utilizó caldo Rappaport Vassiliadis (de las colonias lactosa negativas y sospechosas por su morfología en Agar MC); para la confirmación se usó Agar xilosa, lisina, desoxicolato (XLD) y finalmente caldo Urea. Para los recuentos bacterianos se consideraron únicamente las placas que tuvieron entre 15 a 300 colonias, según lo descrito por Ministerio de Salud del Perú. Dirección General de Salud Ambiental [MINSA/ DIGESA], 2001.

De las muestras de plaqueo ambiental se realizó el conteo de colonias de bacterias y de hongos por placa y, en la identificación de los géneros microbianos (usando el método ya descrito), para hongos, se realizó el recuento total de colonias de mohos y levaduras.

\section{Análisis de datos}

Se realizó una estadística descriptiva mediante diagrama de cajas, representando la mediana y la media del recuento de bacterias mesófilas aerobias, encontradas en las carcasas muestreadas de todos los centros; la prueba t de Student, para determinar la existencia de la diferencia significativa entre los recuentos bacterianos en carcasas de los CFF y CFI, con un nivel de significancia de $\mathrm{p}=0.036$; la prueba $U$ de Mann-Whitney, para determinar la diferencia significativa entre los resultados de los CFF y CFI, con un nivel de significancia de $\mathrm{p}=0.002$. Los resultados fueron esquematizados con el programa Sigmaplot 11.0.

\section{RESULTADOS Y DISCUSIÓN}

El recuento promedio de bacterias mesófilas aerobias en las carcasas fue de 4,91 \pm 0,7 Log $\mathrm{UFC} / \mathrm{cm}^{2}$, en los seis centros de faenamiento (Tabla 2). Dicho resultado fue superior a los 4,01 
\pm 0,03 Log UFC/ $\mathrm{cm}^{2}$ hallado por Molero (2012), en el estado de Zulia (Venezuela), quien muestreó solo el área de la pechuga. Por otra parte, Santamaría (2019), en un estudio de carne de pollo de mercados, en el sur del país, reportó que el 17,3\% de las muestras superó los límites máximos permisibles (LMP) de aerobios mesófilos, considerando M: 10 $, \mathrm{M}: 10^{7}$. Mientras tanto, Pérez y Serrano (2013) reportaron resultados de 3,3 - 3,9 Log UFC/ml, aplicando el método de enjuague de carcasas, en dos centros de faenamiento de Huancavelica en el Perú.

Por otra parte, se halló una correlación positivamente significativa $(r=0,709 ; \mathrm{p}=0,00001)$ entre el recuento de bacterias mesófilas aerobias $\left(\log U F C / \mathrm{cm}^{2}\right)$ y el recuento de enterobacterias (Log UFC $\left./ \mathrm{cm}^{2}\right)$, en las carcasas. El diagrama de cajas, de la Figura 1, muestra que la media del recuento de mesófilos, en las carcasas de los CFI (5,1 $\left.\pm 0,76 \mathrm{Log} \mathrm{UFC} / \mathrm{cm}^{2}\right)$, superó el LMP de $5 \mathrm{Log} \mathrm{UFC} / \mathrm{cm}^{2}$; además, este fue significativamente mayor al valor de la media de los CFF $\left(4,53 \pm 0,38 \mathrm{Log} \mathrm{UFC} / \mathrm{cm}^{2}\right)(\mathrm{p}=0,036)$. Los resultados indican que, de acuerdo con lo establecido por la Norma Técnica Sanitaria No 071-V.01 (MINSA/ DIGESA, 2008), los lotes de las muestras de carcasas de pollo, provenientes de los CFI 3 y CFI 4, serían declarados inaceptables, por superar el LMP $\left(105 \mathrm{UFC} / \mathrm{cm}^{2}\right)$ de bacterias mesófilas aerobias, en más de dos muestras (Tabla 2).

El diagrama de cajas en la Figura 2 muestra que la media del recuento de enterobacterias, en carcasas de los CFI (4,3 Log $\left.\mathrm{UFC} / \mathrm{cm}^{2}\right)$, fue significativamente mayor que en los CFF $(3,67$ $\left.\log \mathrm{UFC} / \mathrm{cm}^{2} ; \mathrm{p}=0,002\right)$. Por su parte, los valores de todos los centros de faenamiento superaron el LMP (2 Log UFC/ $\mathrm{cm}^{2}$ ) establecido por el Servicio Nacional de Sanidad y Calidad Agroalimentaria de Argentina (SENASA, 2016). Teniendo en cuenta lo anterior, según estos resultados y la norma indicada, todos los lotes evaluados deberían haber sido declarados inadmisibles para la venta y para consumo humano.

\section{Figura 1}

Diagrama de cajas del recuento total de bacterias mesófilas aerobias en carcasas de pollo (Log $U F C / \mathrm{cm} 2)$, en centros de faenamiento informales $(n=20)$ y formales $(n=10)$

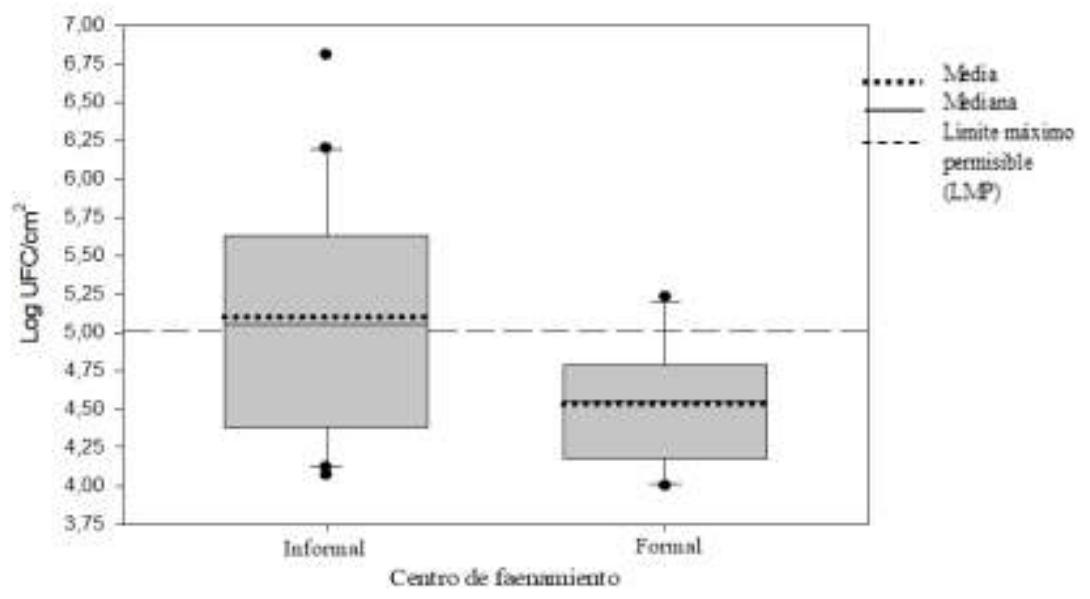




\section{Tabla 2.}

Recuento de bacterias mesófilas aerobias y enterobacterias en carcasas de pollo (Log UFC/ $\left.\mathrm{cm}^{2}\right)$, de los centros de faenamiento de la provincia de Coronel Portillo, Ucayali, en la Amazonía Peruana.

\begin{tabular}{lcc}
\hline $\begin{array}{c}\text { Centro de } \\
\text { Faenamiento }\end{array}$ & $\begin{array}{c}\text { Bacterias mesófilas } \\
\text { aerobias }\end{array}$ & Enterobacterias \\
\hline Formal 1 & $4,5 \pm 0,4$ & $3,7 \pm 0,3$ \\
Formal 2 & $4,5 \pm 0,4$ & $3,6 \pm 0,2$ \\
Informal 1 & $4,7 \pm 0,6$ & $4,1 \pm 0,5$ \\
Informal 2 & $4,6 \pm 0,7$ & $3,8 \pm 0,5$ \\
Informal 3 & $5,1 \pm 0,1$ & $4,4 \pm 0,2$ \\
Informal 4 & $6,0 \pm 0,6$ & $5,5 \pm 0,5$ \\
\hline Total & $4,91 \pm 0,7$ & $4,2 \pm 0,7$ \\
\hline
\end{tabular}

Nota. Para el promedio se consideraron cinco carcasas por centro de faenamiento para el muestreo.

\section{Figura 2.}

Diagrama de cajas del recuento total de enterobacterias en carcasas de pollo (Log UFC/cm $\left.{ }^{2}\right)$, en centros defaenamiento informales $(n=20)$ y formales $(n=10)$

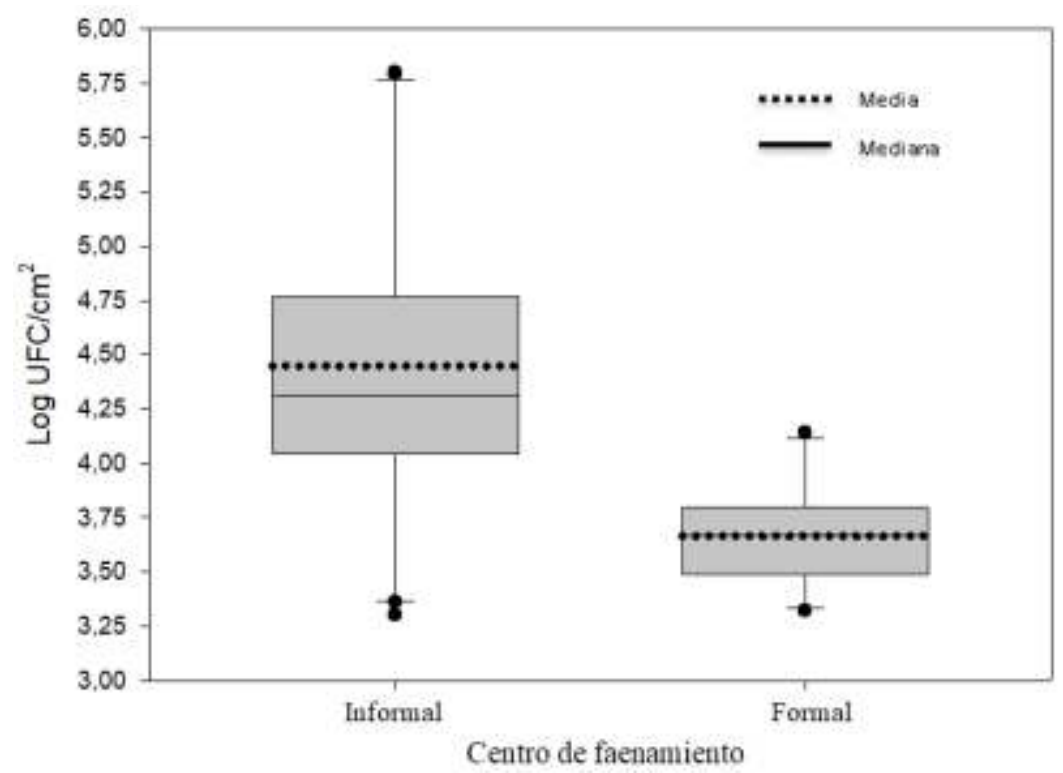

Vale indicar que los porcentajes de especies bacterianas halladas en las carcasas de los pollos se muestran en la Figura 3. Los porcentajes de aislamiento, en el total de las muestras, fueron los siguientes: Escherichia coli (83,3\%), Enterobacter cloacae (80\%), Proteus spp (50\%), Salmonella spp (30\%) y Bacillus spp (20\%); presentándose con mayor frecuencia en las carcasas de pollos de los CFI. Por otro lado, E. coli, E. cloacae y Proteus spp se hallaron en muestras de todos los CF (6/6), con resultados de Bacillus spp en 5/6 y de Salmonella spp. en $4 / 6$. 
Figura 3.

Presencia bacteriana (\%) en carcasas de pollos $(n=30)$ de centros de faenamiento informal (CFI), formal (CFF) y total, de la provincia de Coronel Portillo, Ucayali, Perú

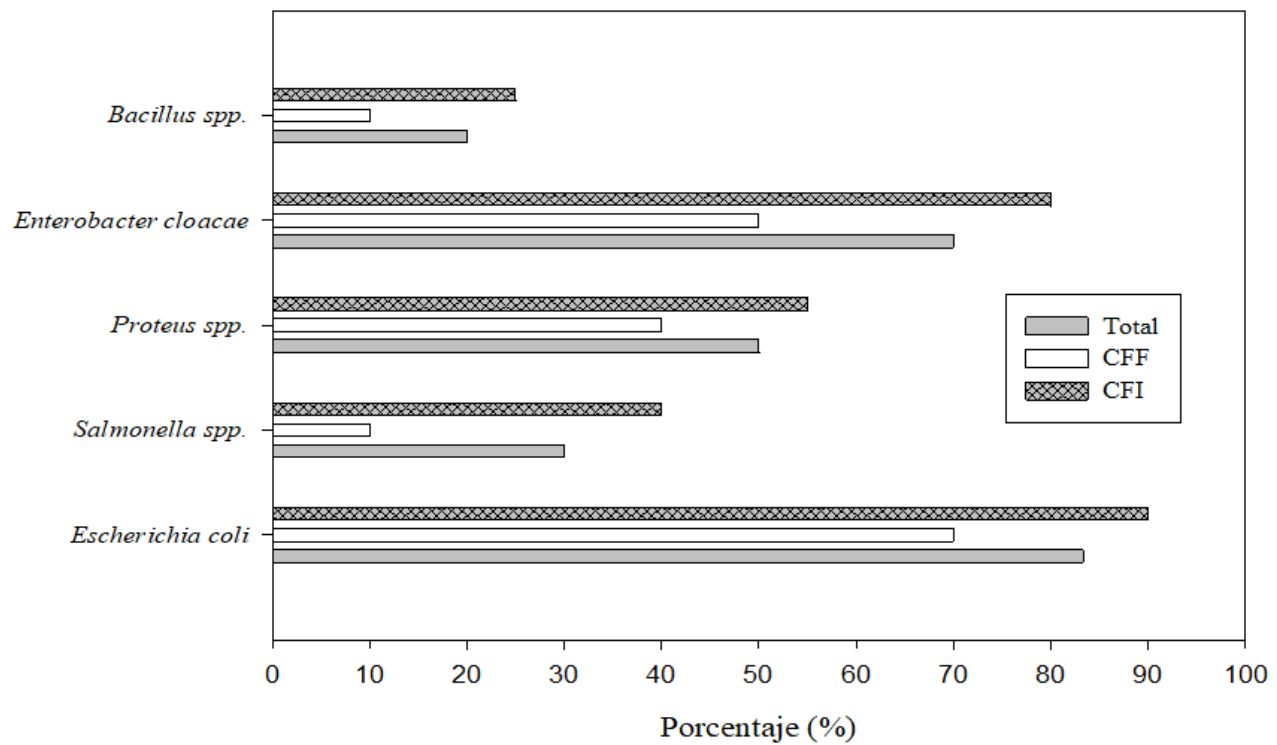

En cuanto a los hallazgos bacterianos, los resultados presentados en este estudio son similares a los hallados por Guerrero, Duarte y Toledo (2007), quienes identificaron E. coli y Salmonella spp. en 29\% y 13\% respectivamente, en muestras de carne de pollo en expendio, en Cuenca, Ecuador. Por su parte, Fernández (2012) encontró E. coli en 47\% de las muestras de pechugas de pollo, en expendio en Loja, Ecuador. En ese mismo sentido, Reinoso (2016) encontró E. coli y Salmonella spp. en 67\% y 5\%, respectivamente, en relación con las muestras de carne de pollo no refrigerado en Lima. A su vez, Zambrano, Lucas, Vilca y Ramos (2013) reportaron presencia de Salmonella spp. en $25,6 \%$ y $35,6 \%$ de las muestras de hisopado cloacal y de enjuague de superficie, respectivamente, en un centro de beneficio clandestino en Lima.

Es importante indicar que la presencia de bacterias en carcasas de pollos dependerá de factores como las condiciones higiénico - sanitarias, durante el transporte que se realiza generalmente en jaulas pequeñas, favoreciendo el mal estado de higiene del ave y la proliferación de bacterias patógenas, entendiendo que este es un asunto que se puede considerar como un renglón fundamental, respecto de la bioseguridad (Ponsa, 2021). Por su parte, el grado de contaminación y sus consecuencias, dependerá de las medidas de control aplicadas durante el procesamiento, almacenamiento, manipulación y distribución, hacia el consumidor final (Lavado, 2017). En este sentido, Pacholewicz et al. (2015) señalan que la presencia de E. coli es un indicador de la higiene del procesamiento, en el matadero.

Ahora bien, aunque la contaminación de las carcasas no implica necesariamente que estas sean un vehículo permanente de bacterias, que puedan llegar al consumidor final, debido a que la 
cocción destruye gran parte de las bacterias superficiales, sí es cierto que podría haber un riesgo sanitario, derivado del consumo de la carne que ha sido manipulada con bajas condiciones de bioseguridad, específicamente si se realiza un mal proceso de cocido, e incluso, también podría generarse a través de la manipulación de las carcasas. Consecuentemente, bacterias como $E$. coli, Salmonella spp. y Staphylococcus aureus son consideradas como agentes infecciosos y toxigénicos que, comúnmente, son encontrados en los alimentos, en forma natural, en productos crudos o añadidos por el hombre, y su presencia generalmente se deriva de una manipulación inadecuada(Da Silva, Matté, Leal y Matté, 2008).

Por otra parte, en el presente estudio, respecto del plaqueo ambiental se identificaron bacterias de los géneros Streptococcus, Bacillus, Staphylococcus y enterobacterias. Los hallazgos evidenciaron que las fuentes de contaminación pueden ser variables y que las prácticas de higiene pueden jugar un papel importante (Pan American Health Organization [PAHO], 2020). El análisis de la calidad del agua utilizada en el proceso de faenamiento, sobre todo la procedente de los centros informales, posiblemente hubiera permitido tener un mejor panorama, sobre los factores que pueden llegar a generar contaminación en las carcasas (Mpundu, Mbewe, Muma, Zgambo y Munyeme, 2019).

A su vez, la alta carga microbiana en los ambientes de los CFI (Tabla 3) estaría determinada, en gran medida, por el tipo de instalaciones que estos poseen, debido a que ellos cuentan con un ambiente en el cual se realiza todo el proceso de faenado y el depósito de jabas, cerca de las mesas para el desplume manual. Además de lo anterior, allí no se realizan una limpieza constante de paredes y pisos, por lo cual se observan desechos del faenado en el área. Por otra parte, las instalaciones no son de construcción sólida y no cuentan con superficies impermeables, las cuales son recomendadas por el reglamento de (Ministerio de Agricultura del Perú. Servicio Nacional de Sanidad Agraria del Perú [MINAG / SENASA], 2007). Incluso, en varios casos, las paredes son de madera y tienen forros de plástico, los cuales se encuentran contiguos a las zonas de lavado de carcasas. Así entonces, se considera que la mejora de las

Tabla 3.

Recuento de microorganismos (Log UFC/placa en bacterias y UFC/placa en hongos) en los ambientes de los centros defaenamiento de pollos, de la de la provincia de Coronel Portillo, Ucayali, en Perú

\begin{tabular}{cccc}
\hline $\begin{array}{c}\text { Centro de } \\
\text { faenamiento }\end{array}$ & $\begin{array}{c}\text { Bacterias mesófilas } \\
\text { Aerobias }\end{array}$ & Enterobacterias & Hongos \\
\hline Formal 1 & 2,95 & 1,45 & 12 \\
Formal 2 & 3,04 & 1,60 & 21 \\
Informal 1 & 3,20 & 1,56 & 19 \\
Informal 2 & 3,38 & 0,78 & 140 \\
Informal 3 & 2,78 & 0,70 & 10 \\
Informal 4 & 3,14 & 1,93 & 33 \\
\hline Total & $3,11 \pm 1,28$ & $1,34 \pm 0,49$ & $39,17 \pm 50,06$ \\
\hline
\end{tabular}


condiciones de higiene y de saneamiento en los $\mathrm{CF}$, podrían a su vez mejorar la vida útil de las carcasas (Tuncer y Sireli, 2008).

En ese mismo orden de ideas, los hongos, principalmente los del género Aspergillus spp, estuvieron presentes en los ambientes de todos los CF. Viegas et al. (2017) encontraron varias especies de Aspergillus en mataderos y en establecimientos avícolas, lo que representa un riesgo ocupacional, por el potencial toxigénico de las especies de este género. Por otra parte, Chmielowiec-Korzeniowska, Tymczyna, Drabik y Krzosek (2016) reportaron la presencia de A. versicolor, un hongo filamentoso patógeno y alergénico, dentro de la sala de una planta de procesamiento de desechos animales, lo cual demuestra un bajo estado sanitario-higiénico del aire, en las salas de procesamiento del lugar y una contaminación del aire en sus inmediaciones.

Finalmente, a pesar de que no hay una norma que categorice los monitoreos microbiológicos ambientales, para los centros de faenamiento, con los resultados del plaqueo ambiental se pudo evidenciar que los centros con mayor ventilación y menor exposición a los excrementos de aves, en sus instalaciones (CFI 3 y CFF 1), tuvieron valores más bajos de bacterias y de hongos, en el recuento del plaqueo. Lo anterior, sugiere un riesgo de contaminación mayor en ambientes cerrados, contrario a lo que recomienda el reglamento, en el cual se establece que los centros deben tener ambientes cerrados, con superficies higienizables y circulación de aire unidireccional (Linares, 2017). No obstante, Hutchison, Walters, Mead, Howell y Allen, (2006) encontraron una débil correlación entre la higiene del proceso, el tiempo, y los indicadores bacterianos, lo que representa un hallazgo limitado.

\section{CONCLUSIÓN}

La evaluación demostró la presencia de varios géneros bacterianos en las carcasas de pollo, en los seis centros de faenamiento, especialmente en los centros informales, con valores en los recuentos de aerobios mesófilos, que sobrepasan los límites máximos permisibles (LMP), además de cargas muy elevadas de bacterias y de hongos en sus ambientes.

\section{REFERENCIAS BIBLIOGRÁFICAS}

Avinews. (2019, 2 de mayo). Avicultura de Perú continúa creciendo este año. AviNews Avicultura Info. https://avicultura.info/avicultura-de-peru-continua-creciendo-este-ano-2019/

Chen, S. H., Fegan, N., Kocharunchitt, C., Bowman, J. P. \& Duffy, L. L. (2020). Impact of poultry processing operating parameters on bacterial transmission and persistence on chicken carcasses and their shelf life. Applied and Environmental Microbiology, 86(12).

https://doi,org/10.1128/AEM.00594-20.

Chmielowiec-Korzeniowska, A., Tymczyna, L., Drabik, A. \& Krzosek, L. (2016). Microbial contamination level of air in animal waste utilization plants. Annals of Agricultural and 
Evaluación microbiológica de carcasas de pollo y ambientes de centros de faenamiento...

Environmental Medicine, 23(1), 54-58. https://doi,org/10.5604/12321966.1196852

Da Silva, M. L, Matté, G. R., Leal, P. M. \& Matté, M. H. 2008. Occurrence of pathogenic microorganisms in fish sold in Sao Paulo, Brazil. Journal of Food Quality, 30(1), 94-110. https://doi.org/10.1111/j.1745-4565.2009.00192.x

Decreto Supremo No 029-2007-AG. Reglamento del Sistema Sanitario Avícola. (2018, 15 setiembre). Ministerio de Agricultura del Perú. https://www.senasa.gob.pe/senasa/sanidad-avicola/

Fernández, W. (2012). Determinación de Escherichia coli por los métodos de placas petrifilm y Agar MacConkey en presas de pollo seleccionadas (pechuga) que se comercializan en la ciudad de Loja. [Tesis de pregrado, Universidad Nacional de Loja-Ecuador]. https://DSPACE.UNL.EDU.EC/JSPUI/BITSTREAM/123456789/5412/1/TESIS2\%20\%E2\%80 $\%$ 9CDETERMINACI\%C3\%93N\%20DE\%20ESCHERICHIA \%20COLI\%20POR\%20LOS\%20 M\%C3\%89TODOS\%20DE\%20PLACAS\%20PETRIFLIM\%20Y\%20AGAR\%20MAC\%20CO NKEY\%20EN\%20PRESAS\%20DE\%20POLLO\%20SELECCIONADAS\%20\%28PECHUGAS $\% 29 \% 20$ QUE\%20SE\%20COMERCIALIZAN.PDF

Guerrero Z, Duarte P, Toledo B. (2007). Enterobacterias patógenas encontradas en carne de pollo para consumo humano. Rev El Salvador 12(1-6).6-1.

Hutchison, M. L., Walters, L. D., Mead, G. C., Howell, M. \& Allen, V. M. (2006). An assessment of sampling methods and microbiological hygiene indicators for process verification in poultry slaughterhouses. Journal of Food Protection, 69(1), 145-153. https://doi.org/10.4315/0362-028x69.1.145.

[INEI] Instituto Nacional de Estadística e Informática del Perú. (2008-2009). Consumo de carnes. https://www.inei.gob.pe

Lavado, D. (2017). Estudio comparativo de la carga bacteriana en carcasas de pollo provenientes de diferentes sistemas de beneficio y comercialización en el Distrito de Trujillo. [Tesis de pregrado, Universidad Privada Antenor Orrego]. https://repositorio.upao.edu.pe/bitstream/20.500.12759/2927/1/REP_MED.VETE_DIEGO.LAV

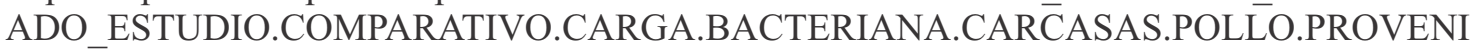
ENTES.DIFERENTES.SISTEMAS.BENEFICIO.COMERCIALIZACI\%C3\%93N.DISTRITO. TRUJILLO.pdf

Linares, C. (2017). Caracterización de infraestructura y equipamiento de los Centros de Faenamiento Avícola en la provincia de Coronel Portillo, (Ucayali). [Tesis de pregrado, Universidad Alas Peruanas]. https://docplayer.es/142215437-Cinthya-isabel-linares-pinedo.html

Ministerio de Salud del Perú. Dirección General de Salud Ambiental. 2001. [MINSA / DIGESA]. (2001). Manual de Análisis microbiológico de alimentos. http://bvs.minsa.gob.pe/local/DIGESA/61_MAN.ANA.MICROB.pdf

Ministerio de Salud del Perú. Dirección General de Salud Ambiental 2008. [MINSA/DIGESA]. 
Evaluación microbiológica de carcasas de pollo y ambientes de centros de faenamiento...

(2008). Resolución Ministerial N591 de 2008. (2008, 27 de agosto). Norma Sanitaria que establece los Criterios Microbiológicos de Calidad Sanitaria e Inocuidad para los Alimentos y Bebidas de Consumo Humano.

https://www.saludarequipa.gob.pe/desa/archivos/Normas_Legales/alimentos/RM591MINSANO RMA.pdf

Ministerio de Agricultura del Perú. Servicio Nacional de Sanidad Agraria del Perú [MINAG/SENASA] (2007). Decreto Supremo No 029-2007-AG. (2018, 15 setiembre). Reglamento del Sistema Sanitario Avícola. https://www.senasa.gob.pe/senasa/sanidad-avicola

Molero, G. (2012). Análisis microbiológico de canales de pollo en los mataderos del Estado Zulia, Venezuela. [Tesis de doctorado, Universidad de Córdoba-España]. https:/helvia.uco.es/xmlui/bitstream/handle/10396/8380/2012000000663.pdf?sequence=1\&isAll owed $=\mathrm{y}$

Mpundu, P., Mbewe, A. R., Muma, J. B., Zgambo, J. \& Munyeme, M. (2019). Evaluation of Bacterial Contamination in Dressed Chickens in Lusaka Abattoirs. Frontiers in Public Health, 7(19). https://doi.org/10.3389/fpubh.2019.00019

Organización de las Naciones Unidas para la Agricultura y la Alimentación / Organización Mundial de la Salud. [FAO /OMS] 2015 (2019, 21 de julio). Codex Alimentarius. Norma general para los contaminantes y las toxinas presentes en los alimentos y piensos. CODEX STAN 193-2015. Enmienda 2010, 2012, 2013, 2104, 2015. http://www.fao.org/fao-who-codexalimentarius/shproxy/en/?lnk=1\&url=https $\% 253 \mathrm{~A} \% 252 \mathrm{~F} \% 252 \mathrm{Fworkspace}$.fao.org $\% 252 \mathrm{Fsites} \% 252 \mathrm{Fcodex} \% 2$ 52FStandards\%252FCXS\%2B193-1995\%252FCXS_193s.pdf

Pacholewicz, E., Swart, A., Schipper, M., Gortemaker, B. G., Wagenaar, J., Havelaar, A. \& Lipman, L. (2015). A comparison of fluctuations of Campylobacter and Escherichia coli concentrations on broiler chicken carcasses during processing in two slaughterhouses. International Journal of Food Microbiology, 205, 119-127. https://doi.org/10.1016/j.ijfoodmicro.2015.04.006

Pan American Health Organization, PAHO. (2021, 07 de mayo). Análisis de peligros y puntos críticos de control (HACCP). PAHO. https://www.paho.org/hq/dmdocuments/2017/food-safetyhacpp-cha-analisis-peligros-puntos-criticos-control.pdf

Pérez, J. y Serrano, F. (2013). Calidad microbiológica de la carne de pollo (Gallus gallus) comercializada en la ciudad de Huancavelica. [Tesis de pregrado, Universidad Nacional de Huancavelica-Perú]. http://repositorio.unh.edu.pe/handle/UNH/743

Pérez, I. (2015). Calidad y seguridad microbiológica de la carne de pollo: con especial referencia a la incidencia de Salmonella, Campylobacter y Listeria Monocytogenes en las distintas etapas de la producción y procesado. [Tesis de doctorado, Universidad de la Rioja-España]. https://dialnet.unirioja.es/servlet/tesis?codigo $=46794$

Ponsa Masurra, F. (2012). Actualización de las mejores técnicas disponibles para el control de Salmonella en avicultura. Selecciones Avícolas, 7-11. 
Evaluación microbiológica de carcasas de pollo y ambientes de centros de faenamiento...

https://fdocuments.es/document/actualizacion-de-las-mejores-tecnicas-causas-mas-comunes-detoxiinfecciones.html

Reinoso, J. (2016). Determinar la presencia de enterobacterias en pollo no refrigerado que se expende en el Mercado 27 de Febrero de la ciudad de Cuenca. [Tesis de magister, Universidad del Azuay-Ecuador]. http://dspace.uazuay.edu.ec/handle/datos/5144

Santamaría, M. (2019). Calidad microbiológica de la carne de pollo expendida en el Mercado Mayorista Miguel Grau del Distrito de Tacna. [Tesis de pregrado, Universidad Nacional Jorge Basadre Grohmann]. http://repositorio.unjbg.edu.pe/handle/UNJBG/3872

Servicio Nacional de Sanidad y Calidad Agroalimentaria. Ministerio de Agroindustria de Argentina. [SENASA] (2016). Resolución 336. (2016, 28 de junio). Parámetros microbiológicos para las carnes de aves, huevos, ovoproductos, especies menores y productos de caza. https://www.argentina.gob.ar/normativa/nacional/resoluci\%C3\%B3n-336-2016-263092

Servicio Nacional de Meteorología e Hidrología del Perú. [SENHAMI]. 2017 (2019, 11 de enero). Mapa Climático del Perú. https://www.senamhi.gob.pe/?p=mapa-climatico-del-peru

Tuncer, B. \& Sireli, U. (2008). Microbial growth on broiler carcasses stored at different temperatures after air- or water-chilling. Poultry Science, 87(4), 793-799. https://doi.org/10.3382/ps.2007-00057

Vera J. (2016). Situación actual de la avicultura peruana. El Sitio Avícola. http://www.elsitioavicola.com

Viegas, C., Faria, T., Caetano, L., Carolino, E., Gomes, A. \& Viegas, S. (2017). Aspergillus spp. prevalence in different Portuguese occupational environments: What is the real scenario in high load settings? Journal of Occupational and Environmental Hygiene, 14(10), 771-785. https://doi.org/10.1080/15459624.2017.1334901

Zambrano, H., Lucas, J., Vilca, M. y Ramos, D. (2013). Determinación de Salmonella spp. en centros de beneficio clandestino de pollos de engorde en Lima, Perú. RIVEP, 24(3), 337-345. https://doi.org/10.15381/rivep.v24i3.2582

Zegarra, J., Palomino, L., Ramos, D., Manzanedo, R., Angulo, C. y Alvarado, A. (2004, septiembre). Clasificación y priorización de los departamentos del Perú según variables epidemiológicas en sanidad avícola. [Conferencia]. XVII Congreso Nacional de Ciencias Veterinarias, Tacna, Perú. 